\title{
Hepatology
}

\section{Hepatocellular Carcinoma in Patients with Chronic Hepatitis C}

\author{
Dmitry Konstantinov, PhD*; Larisa Popova, MD, ScD; \\ Elena Konstantinova, $\mathrm{MD}, \mathrm{PhD}$
}

Samara State Medical University, Samara, the Russian Federation

\begin{abstract}
The purpose of the study was to examine the clinical and epidemiological data in patients with chronic hepatitis $\mathrm{C}$ (CHC) and hepatocellular carcinoma (HCC) before they sought specialized medical care.

The study included 92 patients with CHC. All patients were divided into 2 groups: Group 1 consisted of CHC patients with HCC $(n=45)$, and Group $2(n=47)$ consisted of CHC patients without HCC.

With the development of HCC in CHC patients, clinical manifestations were absent only in $2.2 \%$ of patients. Determining factors in HCC development are male sex, mature age, the maintained HCV replication, moderate and severe fibrosis, disease duration of more than 10 years, and the lack of effect of antiviral treatment. Int J Biomed. 2016;6(3):195-198.).
\end{abstract}

Key Words: chronic hepatitis $\mathrm{C} \bullet$ hepatocellular carcinoma $\bullet$ risk factors $\bullet$ clinical manifestations.

\section{Introduction}

Hepatocellular carcinoma (HCC) is a leading cause of cancer-related death worldwide. ${ }^{[1]}$ In most countries, HCC accounts for $70 \%-85 \%$ of primary liver cancer cases, ${ }^{[2]}$ with the burden of disease expected to increase in coming years. ${ }^{[3]}$ HCC causes $\sim 600,000$ deaths worldwide per year. ${ }^{[1]}$

HCC is a complex disease associated with many risk factors and cofactors. ${ }^{[4,5]}$ Most cases of HCC are secondary to chronic infection with $\mathrm{HBV}$ or HCV. About $10 \%$ to $25 \%$ of $\mathrm{HCC}$ cases worldwide are thought to be a result of $\mathrm{HCV}$ infection. ${ }^{[6,7]}$

There is a need for further investigation of the clinical and pharmacological aspects of this disease. Algorithms for HCC treatment depend on the stage of the disease at diagnosis and the availability of complex therapies ${ }^{[8]}$ However, the disease is incurable in advanced stages, when its management is very expensive and effective only in terms of quality adjusted life years (QALY). ${ }^{[9]}$ According to Bolondi et al. ${ }^{[10]}$ the cost per treatable HCC was $\$ 17,934$ with a cost per life year saved of $\$ 112,993$.

The rating and ranking of risk factors (RFs) for the formation of cirrhosis and primary liver cancer in patients with chronic hepatitis $\mathrm{C}(\mathrm{CHC})$ is a serious health problem.

*Corresponding author: Dmitry Konstantinov, PhD, Samara State Medical University. Russia. E-mail:dk.samgmu@mail.ru
Its relevance is unquestionable and requires immediate development of organizational models of treatment and prevention of viral hepatitis and primary liver cancer, because this pathology is one of the threats to national security.

The purpose of the study was to examine the clinical and epidemiological data in patients with $\mathrm{CHC}$ and $\mathrm{HCC}$ before they sought specialized medical care.

\section{Materials and Methods}

Diagnosis was established based on the clinicallaboratory data as well as the results of the PCR (RNA-HCV) and IEA (anti-HCV). The expression of the hepatic cytolysis syndrome was determined according to the International Classification (Los-Angeles, 1994). Viral loading and the genotype of the $\mathrm{C}$ virus were defined by PCR. A percutaneous liver biopsy was performed to confirm HCC diagnosis and to grade and stage histological disease. Liver biopsies that were at least $1.5 \mathrm{~cm}$ in length and had 3-5 portal tracts were considered as informative. Coded histological sections of liver biopsies were scored independently by two different histopathologists using the Knodell Histology Activity Index (HAI) ${ }^{[1]}$ and Metavir system. ${ }^{[12]} \mathrm{A}$ consensus score was calculated after discussion on the points of differences for comparison of various classification and statistical calculations. Patients with PCC were distributed in stages of the disease according to AJCC TNM $6^{\text {th }}$ edition. ${ }^{[13]}$ 
The study included 92 patients with CHC. All patients were divided into 2 groups: Group 1 consisted of $\mathrm{CHC}$ patients with $\mathrm{HCC}(\mathrm{n}=45)$, and Group $2(\mathrm{n}=47)$ consisted of CHC patients without HCC (Table 1).

\section{Table 1.}

Baseline characteristics of patients

\begin{tabular}{|c|c|c|c|c|}
\hline \multicolumn{2}{|l|}{ Variable } & $\underset{\mathrm{n}=45}{\text { Group }} 1$ & $\underset{n=47}{\text { Group }} 2$ & $P$ \\
\hline \multicolumn{2}{|l|}{ Male, $n(\%)$} & $29(64.4)$ & $26(55.3)$ & \multirow{2}{*}{0.3723} \\
\hline \multicolumn{2}{|l|}{ Female, n(\%) } & $16(35.6)$ & $21(44.7)$ & \\
\hline \multicolumn{2}{|l|}{ Age, y } & $56.0 \pm 2.5$ & $32.1 \pm 2.1$ & 0.0000 \\
\hline \multicolumn{2}{|l|}{ Weight, kg } & $66.1 \pm 3.2$ & $72.8 \pm 2.9$ & 0.1237 \\
\hline \multicolumn{2}{|l|}{ Duration of disease, $y$} & $17.5 \pm 2.7$ & $7.9 \pm 2.1$ & 0.0059 \\
\hline \multirow{3}{*}{ HCV genotype, n(\%) } & $1 b$ & $33(73.3)$ & $27(57.4)$ & 0.1097 \\
\hline & $3 a$ & $7(15.6)$ & $12(25.5)$ & 0.2374 \\
\hline & 2 & $5(11.1)$ & $8(17.0)$ & 0.4158 \\
\hline \multicolumn{2}{|l|}{ METAVIR stage F3 } & $19(42.2)$ & $6(12.8)$ & 0.0015 \\
\hline
\end{tabular}

In accordance with the purpose of the study, we designed a specific observation card, which included demographic data, duration of $\mathrm{HCV}$ infection, routes of $\mathrm{HCV}$ transmission, alcohol consumption, smoking status, and the results of physical examination and laboratory/instrumental investigations.

The study was approved by the local Ethics Committee. Written informed consent was obtained from each patient.

Statistical analysis was performed using the statistical software «Statistica» (v6.0, StatSoft, USA). Baseline characteristics were summarized as frequencies and percentages for categorical variables and as mean \pm SEM for continuous variables. The Mann-Whitney (U Test) was used to compare the differences between groups. Group comparisons with respect to categorical variables are performed using chisquare test. A probability value of $P<0.05$ was considered statistically significant.

\section{Results and Discussion}

Among CHC patients with HCC, 29(64.4\%) were male and $16(35.6 \%)$ female. The average age of patients at the first examination ranged from 40 to 72 years (mean age $56.0 \pm 2.5$ years), with no significant differences between men and women.

A history of icteric forms of acute viral hepatitis (AVH) was found in 5(11.1\%) patients. The presence of HCV infection RFs was found in 39(86.7\%) patients. These patients were those with the following conditions: earlier acute surgical diseases, which were a reason for blood transfusion and surgical interventions (30.8\%); a combination of RFs for infection (professional risk and blood transfusion) (12.8\%); elective surgical operation and parenteral manipulations in hospital (28.2\%); occupational exposure to blood (12.8\%); drug use by injection (10.3\%); and tattoos (5.1\%).

The duration of $\mathrm{HCV}$ infection was determined in 42 patients of Group 1: up to 10 years in $14.3 \%$ of patients, from 10 to 15 years in $33.3 \%$ of patients, and more than 15 years in $52.4 \%$ of patients.

In Group 1, the characteristic clinical signs of the disease (by the frequency of their appearance) were asthenovegetative syndrome(fatigue, irritability, sleep disturbances, a decreased performance, and general weakness, malaise, mood instability, headache), dyspeptic syndrome(loss of appetite, abdominal discomfort, nausea, bloating, belching and vomiting in some patients), and dull aching pain in the epigastric zone or right upper quadrant. Almost all patients of Group 1 had complaints (Table 2); the difference was only in the degree of the severity and various combinations of the complaints.

Table 2.

Clinical syndromes and symptoms in patients of both groups

\begin{tabular}{|l|c|c|c|}
\hline \multicolumn{1}{|c|}{ Clinical manifestations } & $\begin{array}{c}\text { Group 1 } \\
\text { n (\%) }\end{array}$ & $\begin{array}{c}\text { Group 2 } \\
\text { n (\%) }\end{array}$ & $P$ \\
\hline Asthenovegetative syndrome & $44(97.8)$ & $28(59.6)$ & 0.000 \\
\hline Dyspeptic syndrome & $31(68.9)$ & $27(57.4)$ & 0.2557 \\
\hline Hepatomegaly & $37(82.2)$ & $29(61.7)$ & 0.0289 \\
\hline Splenomegaly & $23(51.1)$ & $10(21.3)$ & 0.0028 \\
\hline Hemorrhagic syndrome & $16(35.6)$ & $4(8.5)$ & 0.0017 \\
\hline Right hypochondrium syndrome & $43(95.6)$ & $30(63.8)$ & 0.0002 \\
\hline Icteric skin/sclera & $12(26.7)$ & $2(4.3)$ & 0.0028 \\
\hline Weight loss & $27(60.0)$ & $2(4.3)$ & 0.0000 \\
\hline Arthralgia & $28(62.2)$ & $12(25.5)$ & 0.0004 \\
\hline Myalgia & $26(57.8)$ & $15(31.9)$ & 0.0126 \\
\hline Depression & $19(42.2)$ & $6(12.8)$ & 0.0015 \\
\hline Skin rashes & $5(11.1)$ & $2(4.3)$ & $0.397 *$ \\
\hline
\end{tabular}

*-Yates'p-value

In Group 1, the first clinical manifestations of the disease in $36(80 \%)$ patients were the hepatic manifestations (hepatomegaly, jaundice, an enlarged spleen), whereas in Group 2, these manifestations were found only in 10(21.3\%) patients. In early disease, extrahepatic manifestations were detected in 27(60\%) patients in Group 1 and 12(25.5\%) patients in Group 2. The combination of the hepatic and extrahepatic manifestations occurred in $29(64.4 \%)$ patients in Group 1 and 9 (19.1\%) patients in Group 2.The absence of the hepatic and extrahepatic manifestations was noted only in $3(6.7 \%)$ patients of Group 1 and 19(40.4\%) patients of Group 2. Disease debut with hepatic manifestations was found in 21(74./2\%) men and 7(43.7\%) women, whereas disease debut with extrahepatic manifestations was in $8(50 \%)$ women and $6(20.6 \%)$ men $(\mathrm{p}<0.001)$.

In Group 1, the nonspecific complaints were also frequent: fatigue (weakness and decreased performance) $(97.8 \%)$, headache $(61.1 \%)$, heaviness $(88.2 \%)$ and pain 
in the right upper quadrant $(47.2 \%)$, poor appetite $(57.6 \%)$, epigastric pain $(45.1 \%)$, nausea $(42.4 \%)$, flatulence $(61.1 \%)$, and abdominal discomfort (63.2\%). In addition, itchy skin was found in 4 patients. Among the objective data from the physical examination, we found enlargement of the liver and spleen in $82.2 \%$ and $51.4 \%$ of patients, respectively; hemorrhagic syndrome in $35.6 \%$ of patients; and extrahepatic signs of liver disease as a palmar erythema and vascular "sprockets" in $68 \%$ of patients.

In general, the combination of $\mathrm{CHC}$ and $\mathrm{HCC}$ has no strictly specific clinical symptoms that can help to distinguish this concomitant pathology from other liver diseases. However, the comparative analysis shows the predominance of the asthenovegetative and hemorrhagic syndromes, hepatosplenomegaly, arthralgia, myalgia, depression, and weight loss in patients of Group 1. Clinical manifestations of the disease often did not meet the severity of liver injury; to evaluate the activity and prognosis, we used laboratory, instrumental, and morphological methods of diagnosis.

In Group 1, the degree of inflammatory activity by HAI was as follows: minimal (score 1-3) - 5(11.1\%), mild (score 4-7) - 10(22.2\%), moderate (score 8-12) - 14(31.1\%), and marked (score 13-18) - 16(35.6\%). Distribution of patients by METAVIR stage of liver fibrosis is shown in Fig. 1.

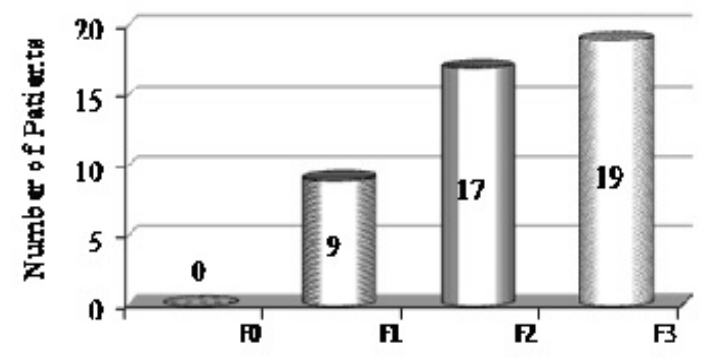

Fig. 1. Distribution of patients by METAVIR stage of liver fibrosis

The distribution of Group 1 patients according to the $\mathrm{HCV}$ genotypes was as follows: genotype $1 \mathrm{~b}-33(73.3 \%)$, genotype $3 \mathrm{a}-7(15.6 \%)$, and genotype $2-5(11.1 \%)$. HCV RNA was detected in $41(91.1 \%)$ patients. The average viral load was $2.3 \times 10^{6} \mathrm{IU} / \mathrm{ml}$.

In Group 1, 18(40\%) patients received the combined antiviral treatment: peginterferon-alpha2a plus ribavirin. However, antiviral treatment did not lead to a sustained virologic response. On the background of antiviral treatment, virological relapse and virological breakthrough were noted in 6 and 12 patients, respectively; 22 people refused to initiate antiviral treatment, and one patient did not receive antiviral treatment due to the presence of contraindications.

Indicators of alpha-fetoprotein (AFP) remained within the normal range (from 0.5 to $2.5 \mathrm{MoM}$ ) in $50 \%$ of patients. In $24 \%$ of patients, AFP increased from 5 to $30 \mathrm{MoM}$, and $26 \%$ of patients had AFP from 170 to $12000 \mathrm{MoM}$. According to
MRI results, the left lobe of the liver was moderately enlarged in $40 \%$ of patient, the right lobe in $10 \%$ of patients, and both lobes in $10 \%$ of patients. The liver size within the age norm was found in $40 \%$ of patients. We found the following localization of the pathological process: $\mathrm{S} 7-60 \%, \mathrm{~S} 8-40 \%$, and the combination of 3 or more segments in $30 \%$ of patients.

The presence of concomitant diseases was noted in $38(84.4 \%)$ patients in Group 1: gastrointestinal disease in $71 \%$ of cases, including $15(33.3 \%)$ patients with two or more comorbidities.

\section{Conclusion}

The clinical picture of $\mathrm{CHC}$ without $\mathrm{HCC}$ was low symptomatic, and clinical signs were absent in $36 \%$ of patients. With the development of $\mathrm{HCC}$ in $\mathrm{CHC}$ patients, clinical manifestations were absent only in $2.2 \%$ of patients. In some patients, the disease was diagnosed in connection with the "accidental" discovery of elevated levels of serum transaminases and/or detection of anti-HCV. Often, especially in women, the first clinical signs of the disease were extrahepatic signs. Determining factors in HCC development are male sex, mature age, the maintained HCV replication, moderate and severe fibrosis, disease duration of more than 10 years, and the lack of effect of AVT.

\section{Competing interests}

The authors declare that they have no competing interests.

\section{References}

1. Venook AP, Papandreou C, Furuse J, de Guevara LL.The incidence and epidemiology of hepatocellular carcinoma: a global and regional perspective. Oncologist. 2010;15 Suppl 4:5-13.

2. Ahmed F, Perz JF, Kwong S, Jamison PM, Friedman C, Bell BP. National trends and disparities in the incidence of hepatocellular carcinoma, 1998-2003. Prev Chronic Dis. 2008;5(3):A74.

3. Llovet JM. Updated treatment approach to hepatocellular carcinoma. J Gastroenterol. 2005;40(3):225-35.

4. Gomaa AI, Khan SA, Toledano MB, Waked I, TaylorRobinson SD. Hepatocellular carcinoma: Epidemiology, risk factors and pathogenesis. World J Gastroenterol. 2008;14(27):4300-8.

5. Di Bisceglie AM. Epidemiology and clinical presentation of hepatocellular carcinoma. J Vasc Interv Radiol. 2002;13(9 Pt2):S169-71.

6. Block TM, Mehta AS, Fimmel CJ, Jordan R. Molecular viral oncology of hepatocellular carcinoma. Oncogene. 2003;22(33):5093-107.

7. Anthony PP. Hepatocellular carcinoma: an overview. Histopathology. 2001;39(2):109-18.

8. Bruix J, Llovet JM. Prognostic prediction and treatment strategy in hepatocellular carcinoma. Hepatology. 2002; 35(3):519-24.

9. Kubo S1, Nishiguchi S, Hirohashi K, Tanaka H, Shuto $\mathrm{T}$, Yamazaki $\mathrm{O}$, et al. Effects of long-term postoperative 
interferon-alpha therapy on intrahepatic recurrence after resection of hepatitis $\mathrm{C}$ virus-related hepatocellular carcinoma: a randomized, controlled trial. Ann Intern Med. 2001;134(10):963-7.

10. Bolondi L, Gaiani S, Casali A, Serra C, Piscaglia F. Screening for the early diagnosis of hepatocellular carcinoma: cost-effectiveness analysis. Radiol Med. 1997; 94(1-2):4-7. [Article in Italian].

11. Knodell RG, Ishak KG, Black WC, Chen TS, Craig R, Kaplowitz N, Kiernan TW, Wollman J. Formulation and application of a numerical scoring system for assessing histological activity in asymptomatic chronic active hepatitis. Hepatology. 1981;1(5):431-5.

12. Bedossa P, Poynard T. The French METAVIR Cooperative Study Group. An algorithm for grading activity in chronic hepatitis C. Hepatology. 1996;24:289-93.

13. American Joint Committee on Cancer. AJCC cancer staging manual Sixth Edition. Springer; Chicago, USA 2002. https://cancerstaging.org/references-tools/deskreferences/ Documents/AJCC6thEdCancerStagingManualPart1.pdf 